\title{
Yet more evidence for a north-south slope in the Australian Height Datum
}

\author{
W E Featherstone \\ Western Australian Centre for Geodesy, Curtin University of Technology, GPO Box U1987, Perth, \\ WA 6845; Phone: +61-8-9266-2734; Fax: +61-8-9266-2703; E-mail: W.Featherstone@curtin.edu.au
}

\begin{abstract}
The results here add significantly to the body of evidence for a systematic north-south error in the Australian Height Datum (AHD). Previous studies based solely on Global Positioning System (GPS) and a gravimetric geoid model have suffered from the 'inseparability problem', where it is not possible to discriminate between errors in the AHD and geoid. Instead, this study compares horizontal gradients of the AUSGeoid98 regional gravimetric geoid model with totally independent astrogeodetically observed vertical deflections at 741 Laplace stations across Australia. These comparisons do not show any significant latitude-dependent residuals, thus significantly reducing the likelihood of a north-south slope in AUSGeoid98. Subsequently using GPS and AUSGeoid98, now that the inseparability problem has been addressed, there is very compelling evidence for a real northsouth slope of $\sim 1.5 \mathrm{~m}$ in the AHD.
\end{abstract}

\section{INTRODUCTION}

Even at the time when the Australian Height Datum (AHD) was established in 1971, it was known to contain distortions (Roelse et al., 1975). These can be attributed to a combination of: the quality of the, mainly third-order, spirit-levelling observations used (cf. Leppert, 1967; Angus-Leppan, 1975; Morgan, 1992; Kearsley et al., 1998); the neglect of observed gravity corrections to the spirit-levelling observations (cf. Featherstone and Kuhn, 2005; Holloway, 1988; Tenzer et al., 2005); and, most importantly, fixing AHD heights to zero at mean seallevel (MSL) observed for 2 or 3 years at 32 tide-gauges around the Australian mainland and Tasmania. In addition, several of these tide-gauges were located upstream from the mouth of the river. This fixing of the tide-gauges is widely thought to cause the dominant north-south distortion because sea-surface topography was not accounted for in the fixed-network adjustment of the adopted AHD (e.g., Featherstone, 1998, 2001, 2004; Johnston and Luton, 2001). 
Numerous previous studies have been conducted to add evidence to, and help quantify, the large-scale distortions in the AHD (e.g., Morgan, 1992; Featherstone and Stewart, 1998; Featherstone, 2001, 2004; Johnston and Luton, 2001; Baran et al., 2005). The more recent studies use regional gravimetric geoid models, which are also known to contain longwavelength errors, principally due to errors in the global geoid model used as their basis, but also due to the propagation of errors from the terrestrial gravity and terrain data used in their construction. Using the approximate (because of curvature and torsion of the plumbline) relation $H=h-N$, where $H$ is the AHD height, $h$ is the Global Positioning System (GPS)observed ellipsoidal height and $N$ is the geoid-ellipsoid separation, it is not easy to isolate the discrepancy to only one of $h, H$ or $N$. Since GPS ellipsoidal heights are accurate to within, say, 10 cm (e.g., Stewart, 1998), the observed discrepancy (Featherstone, 2001, 2004; Baran et al., 2005) probably lies in one or both of $H$ or $N$. This is termed the 'inseparability problem' (cf. Featherstone, 2004).

Acknowledging the quasi-independent evidence already given by Baran et al. (2005) for the north-south slope in the AHD, this paper presents a more independent, and thus more compelling, determination of the north-south slope in the AHD. It uses astrogeodetically observed vertical deflections at 741 Laplace stations across Australia to verify that the AUSGeoid98 (Featherstone et al., 2001) geoid model does not contain a north-south slope. Given this verification, it is then possible to use more recent co-located GPS and AHD data to confirm the north-south slope in the AHD, since GPS is not yet known to contain any northsouth error dependency, certainly not at the metre level. This avoids the abovementioned separability problem, thus giving rather firm evidence for the north-south slope in the AHD.

\section{VERTICAL DEFLECTIONS}

The deflection/deviation of the vertical is the angular difference between the ellipsoidal surface normal and the direction of the plumbline (field-line of the Earth's gravity field) at the same point (e.g., Heiskanen and Moritz, 1967; Bomford, 1980; Jekeli, 1999; Featherstone and Rüeger, 2000). By long-standing convention, it is divided into north-south and east-west components, and is typically a few seconds of arc in magnitude, though it may reach over a minute in regions of extremely rugged topography (e.g., Bomford, 1980). In Australia, the deflections are typically less than 30" (Featherstone and Rüeger, 2000). Nevertheless, the total deflection of the vertical has increased systematically by 6 ” due to the introduction of the GDA94 (Featherstone and Rüeger, 2000). 
The Pizzetti deflection at the geoid (e.g., Jekeli, 1999) can be determined gravimetrically, either directly from the Vening-Meinesz integral or indirectly from the horizontal gradients of a geoid model computed via Stokes’s integral (e.g., Heiskanen and Moritz, 1967; Featherstone and Rüeger, 2000). On the other hand, the Helmert deflection at the Earth's surface (e.g., Jekeli, 1999) can be observed by taking the difference between Laplace astrogeodetic (i.e., observed via stars) latitude and longitude and geodetic latitude and longitude, scaled by latitude (e.g., Bomford, 1980; Featherstone and Rüeger, 2000). The [small] difference between Pizzetti and Laplace-Helmert deflections is due to the angular curvature and torsion of the plumbline as it passes through the topography (geoid to Earth's surface). These are notoriously difficult to estimate, but are probably less than a second in Australia because of the relatively benign topography and its low average elevation.

The data used in this study come from totally independent sources. A total of 741 Laplace-Helmert deflections (Figure 1) were supplied by Geoscience Australia (Steed, 2000 pers. comm.). These were derived from Laplace stations observed as part of the establishment of the Australian Geodetic Datum 1966, AGD66 (e.g., Bomford, 1967; Lines, 1992). At a Laplace station, precisely timed angular observations by theodolite are made to the stars to determine astronomic latitude, longitude and azimuth. Given the astrogeodetic and geodetic latitudes and longitudes of the same ground marks, the difference (scaled by latitude) yields the vertical deflections (e.g., Featherstone and Rüeger, 2000, equations 10 and 11).

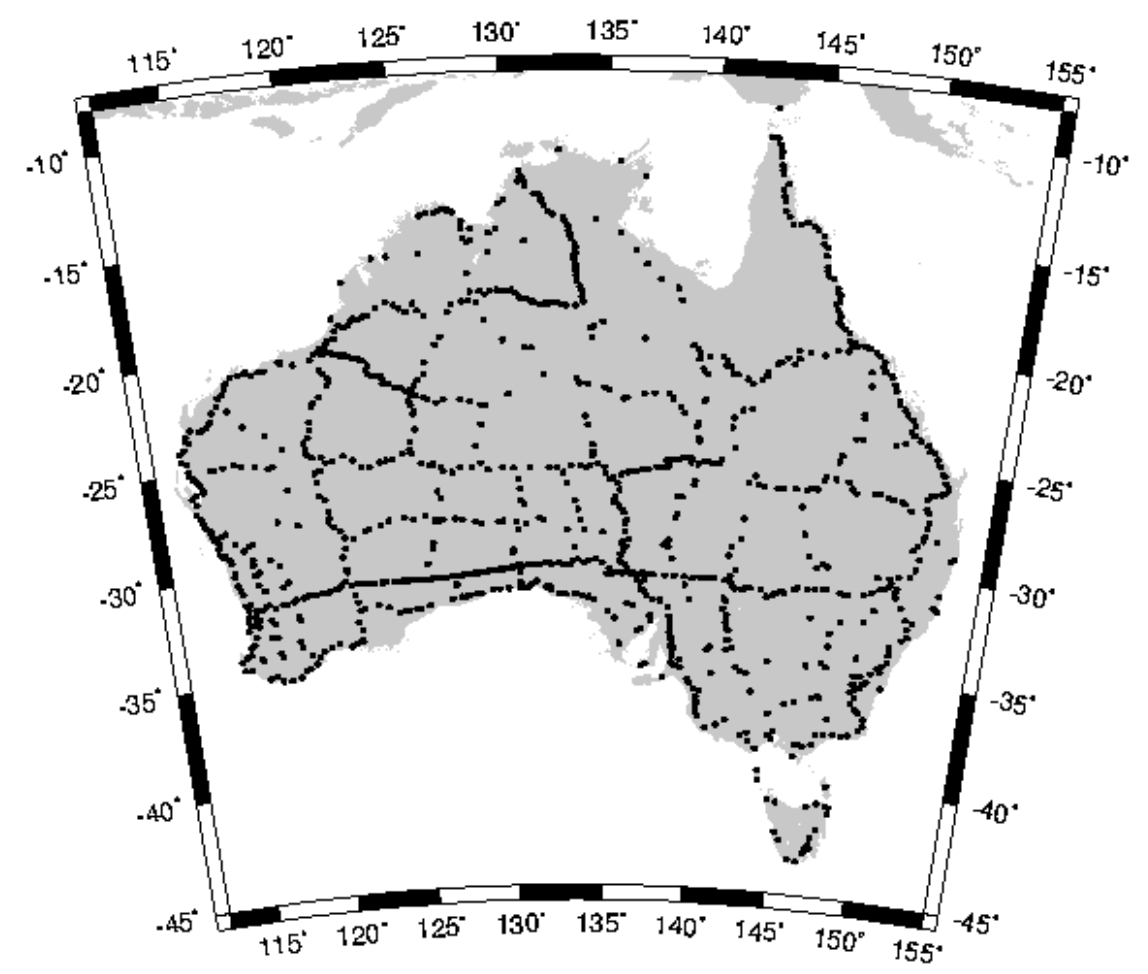

Figure 1. Coverage of the 741 Laplace stations used to evaluate the AUSGeoid98 vertical deflection model [Lambert projection] 
The geodetic coordinates $(\varphi, \lambda)$ of the Laplace stations are on the GDA94 datum, which resulted from a readjustment (not transformation) of terrestrial- and space-geodetic observations. Since the astrogeodetic or natural coordinates $(\Phi, \Lambda)$ were observed at the Earth's surface and the GDA94 coordinates refer to the geocentric GRS80 ellipsoid, this dataset comprises Laplace-Helmert vertical deviations with reference to the GRS80 ellipsoid.

Uncertainty estimates for these Laplace-Helmert deflections are quite difficult to ascertain, principally due to chronometer and theodolite errors in the Laplace observations at the time that they were observed (circa 1960s and earlier). Conservatively, the astrogeodetic latitude and longitude of the Laplace station are probably accurate to 30-50m, or maybe more. This crude estimate is based on the typical one-arc-second specification for a high-precision theodolite, and increased for chronometer and observer errors. The GDA94 latitude and longitude are probably accurate to less than $1 \mathrm{~m}$. Knowing that $31 \mathrm{~m}$ on the Earth's surface is approximately equivalent to arc-second in latitude (and longitude, but scaled by latitude for meridional convergence), this loosely indicates an accuracy of the Laplace-Helmert vertical deflections of 1-2 arc-seconds, or possibly worse.

Uncertainty estimates for the AUSGeoid98-Pizzetti deflections are also quite difficult to ascertain (cf. Featherstone and Rüeger, 2000). Any geoid error common/correlated to adjacent points used to compute the gradients will cancel on differencing, but high-frequency or uncorrelated geoid errors will become amplified on differencing. This noise-amplification is a well-known undesirable property of differentiation. Assuming an error of 10-20 mm over the AUSGeoid98 grid spacing of 2-arc-minutes $(\sim 3.6 \mathrm{~km})$, a crude error estimate is 1 arcsecond.

\section{VERIFICATION OF HORIZONTAL GEOID GRADIENTS}

The AUSGeoid98-Pizzetti vertical deflections were bi-cubically interpolated from the 2-arcminute by 2-arc-minute pre-computed grid to the GDA94 horizontal locations in Figure 1 using the Winter software (http://www.ga.gov.au/geodesy/ausgeoid/) in bicubic interpolation mode. Table 1 shows the descriptive statistics of the differences between the Laplace-Helmert and the AUSGeoid98-Pizzetti vertical deflections, both before and after the removal of four suspected outliers with a difference of greater than 5-arc-seconds in any deflection component. This is roughly a four-sigma rejection. Descriptive statistics are sufficient because the distribution of the differences is reasonably normal. 
From Table 1, the standard deviation of the differences after outlier-removal is \pm 0.9 " in the east-west and $\pm 1.1 "$ in the north-south components over the whole of Australia. This validates the crude estimate made by Featherstone and Rüeger (2000). It also indicates that the conservative accuracy estimates for the Laplace-Helmert and the AUSGeoid98-Pizzetti vertical deflections given earlier are reasonable, and that the curvature and torsion of the plumbline in Australia are also small.

\begin{tabular}{|l|c|c|c|c|}
\hline & \multicolumn{2}{|c|}{ All 741 stations } & \multicolumn{2}{c|}{ After removal of four outliers } \\
\hline & $\begin{array}{l}\text { East-west } \\
\text { deflection }(\eta)\end{array}$ & $\begin{array}{l}\text { North-south } \\
\text { deflection }(\xi)\end{array}$ & $\begin{array}{l}\text { East-west } \\
\text { deflection }(\eta)\end{array}$ & $\begin{array}{l}\text { North-south } \\
\text { deflection }(\xi)\end{array}$ \\
\hline Max & 17.83 & 7.79 & 4.56 & 4.05 \\
\hline Min & -4.05 & -12.65 & -4.05 & -3.62 \\
\hline Mean & -0.23 & -0.09 & -0.26 & -0.07 \\
\hline Median & -3.81 & -0.03 & -0.23 & -0.03 \\
\hline Standard deviation & 1.09 & 1.30 & 0.86 & 1.11 \\
\hline
\end{tabular}

Table 1. Descriptive statistics (in arc-seconds) of the fit of AUSGeoid98-derived Pizzetti vertical deviations to astrogeodetically derived Laplace-Helmert vertical deviations.

Next, it is important to determine if there are any systematic, notably north-south, trends in the differences between the AUSGeoid98-Pizzetti and Laplace-Helmert vertical deviations. Here, it is only necessary to present the north-south deflection as a function of latitude, since this will be the most dependent on a north-south slope in AUSGeoid98. It is acknowledged that the curvature and torsion of the plumbline could come into play here, but inspection of Featherstone and Rüeger (2000, Figures 2 and 3) shows no geological- or topographic-driven reason for a north-south bias in the deflections. This linear trend analysis will determine if there is any north-south slope in AUSGeoid98, thus permitting a solution to the inseparability problem. 


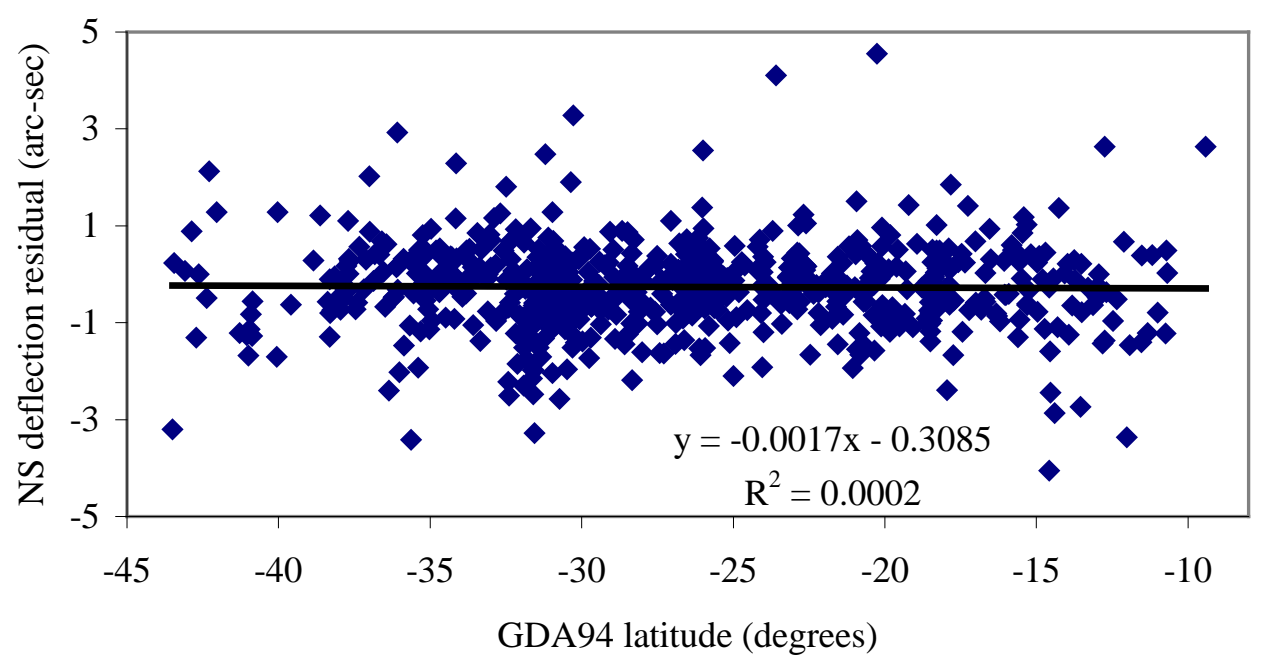

Figure 2. Differences between Laplace-Helmert and AUSGeoid98-Pizzetti north-south vertical deviations (arc seconds) as a function of GDA94 latitude (degrees); 737 points

Figure 2 shows unweighted (because no variances are available for the individual data points) linear regression of the differences between the Laplace-Helmert and AUSGeoid98Pizzetti north-south vertical deviations, after the removal of the four suspected outliers (cf. Table 1). From the regression and R-squared coefficients in Figure 2, it is clear that there is virtually no north-south trend in the residuals. Given that there is no reason to suspect a north-south trend in the Laplace-Helmert vertical deflections, this indicates that there is no north-south slope in AUSGeoid98. As such, the ‘inseparability problem’ has been solved, and it is now possible to compare AUSGeoid98, GPS and AHD data to show that, as there is no north-south trend in the GPS or AUSGeoid98 data, so the trend must be due to the AHD data.

\section{PROOF OF THE NORTH-SOUTH AHD SLOPE}

Figure 3 shows unweighted (again, because no variances are available for the individual data points) linear regression of the differences between co-located GPS-AHD heights and bicubically interpolated AUSGeoid98 heights for the 254 points used by Featherstone and Sproule (2005). No outliers were removed. From the regression and R-squared coefficients in Figure 3, there is a significant north-trend in the residuals.

Since there is no documented north-south bias in GPS-derived ellipsoidal heights, certainly not at the metre level, and the previous section has lessened the probability of a north-south slope in AUSGeoid98, the only culprit for the north-south trend in Figure 3 is the AHD heights. It is also interesting to observe that the regression and R-squared coefficients in 
Figure 3 agree very well with the alternatively derived estimates (slope of $\sim+0.026 \mathrm{~m} /$ degree; R-squared $=0.58$ ) given by Baran et al. (2005) for the same GPS-AHD data, but for a geoid model computed from Newtonian integration of topographic masses.

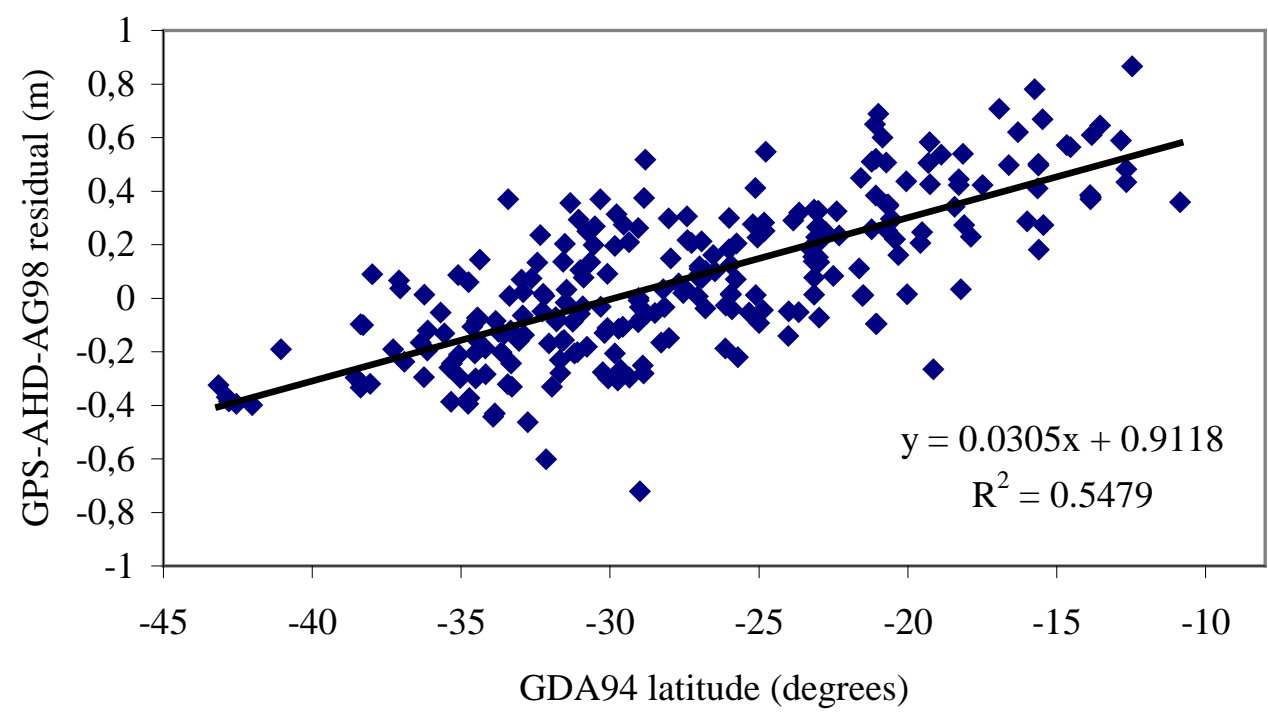

Figure 3. Differences between GPS-AHD and AUSGeoid98 heights (metres) as a function of GDA94 latitude (degrees); 254 points

\section{CONCLUSIONS AND DISCUSSION}

Using Laplace-Helmert vertical deflections, which are a totally independent data source, has verified that there is no significant north-south slope in the AUSGeoid98 gravimetric geoid model of Australia. As a by-product, the precision of the AUSGeoid98 vertical deflections is of the order of one arc-second, which confirms the unquantified estimate given by Featherstone and Rüeger (2000). The verification of no significant north-south slope in AUSGeoid98 solves the 'separability problem' (Featherstone, 2004), where it was previously not easy to discriminate between trends in the AHD or in AUSGeoid98.

As such, the north-south trend between GPS, AHD and AUSGeoid98 (Figure 3) can be more convincingly attributed to a north-south slope in the AHD. Indeed, this value of $\sim 1.5 \mathrm{~m}$ is consistent with estimates made in earlier studies, including the creators of the AHD. Of course, this leads to the question of redefining the AHD to remove this slope, as well as other errors, using improved datasets and models, which will be the subject of a later paper.

In addition, the north-south AHD slope will propagate into the computed gravity anomalies used to compute the regional gravimetric geoid model. These very-longwavelength effects were reduced in AUSGeoid98 by the high-pass filtering properties of the 
modified kernel and limited integration cap (Featherstone et al., 2001). However, work is currently underway on a new Australian geoid model, and tests are planned where this effect is modelled and removed before geoid computation.

\section{ACKNOWLEDGEMENTS}

I would like to thank the Australian Research Council (ARC) for funding my research on the Australian geoid and AHD through grants A49331318, A39938040 and DP0211827, and Jim Steed and Gary Johnston at Geoscience Australia for providing data. I would also like to thank the reviewers (Bill Kearsley and Peter Morgan) for their very constructive comments on an earlier version of this manuscript. Figure 1 was produced with the public domain Generic Mapping Tools (Wessel and Smith, 1998). The revisions to this work were completed at the Geodätisches Institut, Universität Stuttgart, Germany, while I was an Alexander von Humboldt Fellow through award number 1120942.

\section{REFERENCES}

Angus-Leppan, P.V. (1975) An investigation of possible systematic errors in levelling along the eastern coast of Australia, UNISURV Report G-23, School of Surveying, University of New South Wales, Sydney, Australia, pp. 80-91

Baran, I., M. Kuhn, S.J. Claessens, W.E. Featherstone, S.A. Holmes and P. Vaníček (2005) A synthetic Earth gravity model designed specifically for testing regional gravimetric geoid determination algorithms, Journal of Geodesy, vol. 80, no. 1, pp., doi 10.1007/s00190-005-0002$\mathrm{z}$

Bomford, A.G. (1967) The geodetic adjustment of Australia, 1963-1966. Survey Review, vol. XIX, no. 144, pp. 52-71

Bomford, G. (1980) Geodesy, fourth edition, Oxford University Press, 700 pp

Featherstone, W.E. (1998) Do we need a gravimetric geoid or a model of the base of the Australian Height Datum to transform GPS heights? The Australian Surveyor, vol. 43, no. 4, pp. 273-280

Featherstone, W.E. (2001) Prospects for the Australian Height Datum and geoid model, in: Adam, J. and Schwarz, K-P. (eds) Vistas for Geodesy in the New Millennium, Springer, Berlin Heidelberg New York, pp. 96-101

Featherstone, W.E. (2004) Evidence of a north-south trend between AUSGeoid98 and the AHD in southwest Australia, Survey Review, vol. 37, no. 291, pp. 334-343

Featherstone W.E. and M.P. Stewart (1998) Possible evidence for systematic distortions in the Australian Height Datum in Western Australia, Geomatics Research Australasia, no. 69, pp. 1-14

Featherstone, W.E. and J.M. Rüeger (2000) The importance of using deviations of the vertical in the reduction of terrestrial survey data to a geocentric datum, The Trans-Tasman Surveyor, vol. 1, no. 3, pp 46-61 [Erratum in The Australian Surveyor vol. 47, no. 1, pp. 7]

Featherstone, W.E. and D.M. Sproule (2005) Fitting AUSGeoid98 to the Australian Height Datum using GPS data and least squares collocation: application of a cross-validation technique, Survey Review, vol. 38, no. 301 (in press)

Featherstone, W.E. and M. Kuhn (2005) Height systems and vertical datums: a review in the Australian context, Journal of Spatial Science, vol. 51, no. 1, pp. 21-42 
Featherstone, W.E., J.F. Kirby, A.H.W. Kearsley, J.R. Gilliland, G.M. Johnston, J. Steed, R. Forsberg, M.G. Sideris (2001) The AUSGeoid98 geoid model of Australia: data treatment, computations and comparisons with GPS-levelling data, Journal of Geodesy, vol. 75, nos. 5-6, pp. 313-330, doi: 10.1007/s001900100177

Heiskanen, W.A. and Moritz, H. (1967) Physical Geodesy, WH Freeman \& Co, San Francisco, USA, $364 \mathrm{pp}$

Holloway, R.D. (1988) The integration of GPS heights into the Australian Height Datum, UNISURV Report S33, School of Surveying, The University of New South Wales, Sydney, Australia, 151 $\mathrm{pp}$

Jekeli, C. (1999) An analysis of vertical deflections derived from high-degree spherical harmonic models, Journal of Geodesy, vol. 73, no. 1, pp. 10-22, doi: 10.1007/s001900050213

Johnston, G.M. and G.C. Luton (2001) GPS and the Australian Height Datum, Proceedings of the Fifth International Symposium on Satellite Navigation Technology and Applications, in: K. Kubik, C. Rizos and W.E. Featherstone (eds), Canberra, July [CD-ROM]

Kearsley, A.H.W., G.J. Rush and P.W. O’Donell (1988) The Australian Height Datum - problems and proposals, The Australian Surveyor, vol. 34, no. 4, pp. 363-380

Leppert, K. (1967) Problems encountered in the use of third order levelling for the national levelling grid, in: Angus-Leppan, P.V. (ed) Control for Mapping by Geodetic and Photogrammetric Methods, The University of New South Wales, Sydney, pp. 123-134

Lines, J.D. (1992) Australia on Paper - The Story of Australian Mapping, Fortune Publications, Box Hill, Australia

Morgan, P.J. (1992) An analysis of the Australian Height Datum: 1971, The Australian Surveyor, vol. 37, no. 1, pp. 46-63

Roelse A., H.W. Granger and J.W. Graham (1975) The adjustment of the Australian levelling survey 1970 - 1971 second edition, Technical Report 12, Division of National Mapping, Canberra

Stewart, M.P. (1998) How accurate is the Australian National GPS Network as a framework for GPS heighting?, The Australian Surveyor, vol. 43, no. 1, pp. 53-61

Tenzer, R., Vaníček, P., Santos, M., Featherstone, W.E. and Kuhn, M. (2005) Rigorous determination of the orthometric height, Journal of Geodesy, vol. 79, nos 1-3, pp. 2-92, doi: 10.1007/s00190005-0445-2

Wessel, P. and W.H.F. Smith (1998) New, improved version of Generic Mapping Tools released: EOS - Transactions of the American Geophysical Union, vol. 79, no. 47, pp. 579 